\title{
The Lived Experience of Middle-Aged Women with New York Heart Association Class III Heart Failure: A Pilot Study
}

Jennifer Wayment Allen, MS, APRN-BC; Cynthia Arslanian-Engoren, PhD, RN, ACNS-BC, FAHA; Judith Lynch-Sauer, PhD, RN

$\mathrm{H}$ eart failure (HF) is a clinical syndrome with symptoms that significantly impact the daily lives of affected women. Approximately 2.6 million women in the United States are currently diagnosed with HF, rates similar to those found in men. ${ }^{1}$ However, compared to men with HF, women tend to be older when initially diagnosed, live longer with the disease, and are more likely to die each year from HF. ${ }^{1}$ Women with HF also report poorer quality of life, ${ }^{2-4}$ impaired physical functioning, ${ }^{5}$ difficulty sleeping, ${ }^{4}$ emotional disturbances, ${ }^{6,7}$ reduced energy, ${ }^{4,8}$ and problems with housework $^{4}$ and their social life. ${ }^{5}$

Despite the additional burdens of HF upon women and a nearly equal prevalence of the disease in men and women, men comprise the majority of HF research subjects. ${ }^{1}$ This underrepresentation of women in HF research is not limited to drug trials alone, but also in studies addressing the impact of the disease on quality of life. ${ }^{9}$ Additionally, studies examining quality of life in HF patients have primarily used a quantitative approach, $2,3,5,6,10,11$ with few published qualitative studies and only 2 that specifically examined women with the disease. $^{12,13}$ Of these studies, neither specifically investigated women with New York Heart Association (NYHA) class III HF, a functional class where HF symptoms are induced by less than ordinary physical exertion resulting in marked limitations to physical activ-
Although heart failure (HF) is equally prevalent in men and women, women with $H F$ are more likely to report decreased quality of life and are more likely to die of the disease compared with men. Moreover, HF has been studied less extensively in women and no study has specifically addressed women with New York Heart Association (NYHA) class III HF using a qualitative method. This pilot study sought to gain insight into the lived experience of women with NYHA class III HF. Using a phenomenological approach, interviews obtained from 4 middle-aged women with NYHA class III HF were analyzed using the Giorgi method of data analysis. Five themes emerged: (1) developing a new conception of self, (2) conceding physical limitations, (3) enduring emotional heartache, (4) accepting support, and (5) rejuvenating through rest. This study provides a beginning to our understanding of the lived experience of women with NYHA class III HF. However, further exploration is needed to increase our knowledge of HF in women, particularly among diverse populations. Prog Cardiovasc Nurs. 2009;24:96-101. ${ }^{\circ} 2009$ Wiley

Periodicals, Inc.

From the School on Nursing, University of Michigan, Ann Arbor, MI Address for correspondence:

Jennifer Wayment Allen, MS, APRN-BC, School on Nursing, University of Michigan, Ann Arbor, MI

E-mail: jenall@umich.edu

Manuscript received October 13, 2008; revised February 8, 2009; accepted April 21, 2009

ity. ${ }^{14}$ As a result, inadequate knowledge exists as to what it is like for women to live with NYHA class III HF.

\section{PURPOSE}

This study sought to better understand the lived experience of women with NYHA class III HF from the perspective of women living with the disease. Results obtained in this study provide a beginning to our understanding of the perspective and meaning middle-aged women with stage III HF attribute to their disease.

\section{PHILOSOPHICAL FRAMEWORK} Descriptive phenomenology, a philosophy first developed by Edmund Husserl ${ }^{15}$ provides the theoretical underpinnings for this study. Husserl believed that human understanding of the world is dependent on the appearance of things, termed phenomtermed noumena. ${ }^{16}$ Husserl emphasized human experience is interconnected with and forms the objective world and that it is the meaning and the perspective that individuals attach ena, and not upon the thing itself, 
to an experience that make it significant. $^{15}$

This philosophical framework provides the foundation for a research perspective that a deeper understanding of a given phenomenon can be obtained through exploring the experience of those living that phenomenon. ${ }^{17}$ Congruent with the metaparadigm of nursing, Husserl maintained that man and environment are interconnected. ${ }^{15} \mathrm{Be}$ cause of this, phenomenologists espouse the idea that experiences studied in context provide a better understanding of the richness and meaning of a phenomenon than withdrawing context to establish causality. While quantitative methods aim to eliminate the confounding influence of context, a phenomological qualitative approach embraces context as an essential component of the research process, needed to better perceive the integral nature of man and his environment. ${ }^{16}$

In phenomenology it is important for the researcher to suspend or "bracket" any presuppositions about the phenomenon being studied in order to maintain an open perspective to the emerging data. ${ }^{16}$ The authors' perspective, "bracketed" aside until after themes were identified, was that HF had profound impact on women's lives, affecting their physical, social, emotional, mental, spiritual, and economic functioning.

\section{METHOD}

Institutional Review Board approval to conduct this study was obtained before initiation of the study. Using a phenomenological approach, a convenience sample of 4 women living with NYHA class III HF was obtained. Potential participants were screened for inclusion by a HF case manager employed in a university affiliated cardiology practice using the following criteria. Participants had to be: (1) female, (2) diagnosed with NYHA class III HF, (3) at least 21 years of age, (4) able to verbally articulate their experience with HF, and (5) willing to participate in an audiotape recorded, semistructured telephone interview.
Excluded from the study were females who could not speak or understand English or who had a hearing or cognitive impairment that prohibited a telephone interview. Consecutive women with class III HF were recruited until redundancy in description was obtained. Adequacy of the sample was determined when redundancy in description was obtained $[\mathrm{n}=4]$.

Once potential participants were identified the researcher telephoned each to provide additional information about the study. If the potential participant agreed to be a part of the study written informed consent was obtained via mail, before conducting the interview. All potential participants approached by the researcher consented to participate and no participant withdrew before study completion.

\section{Data Collection Procedure}

Telephone interviews were conducted with each participant at a mutually agreed upon time and date. As many of the patients in the cardiologist's practice did not live locally and received the majority of their follow-up care via the telephone, a telephone interview was selected to minimize participant burden related to traveling for a face-to-face interview. Also, because data collection took place during the winter months, a telephone interview prevented unsafe winter travel. All interviews were completed in 1 telephone conversation.

During the interview participants were asked to describe what it was like to live with NYHA class III HF and to share all the thoughts and feelings they could recall about living with the disease. When a participant felt she had completely described her experience with HF the interviews were considered complete. Using techniques of active listening at the close of the interview, a brief summary of the described lived experience was presented to the participant for clarification and feedback. All interviews were audiorecorded and transcribed verbatim.

\section{Data Analysis}

The Giorgi ${ }^{18}$ method of data analysis was selected to analyze the narrative descriptions because of its emphasis on maintaining a sense of the whole during the process of data analysis, compatible with the holistic philosophy of nursing. ${ }^{19}$ The unit of analysis was the collective experience of the 4 participants. The 5 steps of the Giorgi ${ }^{18}$ analytic method included:

Step 1.The researcher read the data multiple times in its entirety to gain a sense of the whole. Transcriptions were compared with the oral descriptions to ensure content accuracy.

Step 2. The data were read again in a slow, purposeful manner. Transitions in the data were examined to identify individual units of meaning. Investigators dwelled on the data in order to understand the experience from the perspective of the women who experienced it.

Step 3. In a reflective, intuitive process individual units of meaning were related to each other in order to develop themes that captured the essence of the participants' experience.

Step 4. Concepts were developed that captured the meaning of each thematic category identified. Focal meanings were identified.

Step 5. The focal meanings were integrated and synthesized into a structural description of the meaning of the lived experience. The structural description is a concise statement of the lived experiences that completely and exhaustively captures the essence of the phenomenon as described by the participants.

During data analysis, the second and third authors, experienced qualitative, phenomenological researchers, offered support to the primary investigator. Several discussions were held to ensure the credibility of the data. All themes were discussed and original transcripts reviewed to resolve disagreements. Initially, 7 themes were identified. However, upon further reflection and during consultation among the researchers, the 7 themes were reduced to 5 higher-order 
Table. Participant Demographics

\begin{tabular}{|c|c|c|c|c|c|c|}
\hline PARTICIPANT & ETHNICITY & AgE & $\begin{array}{l}\text { MARITAL } \\
\text { StATUS }\end{array}$ & $\begin{array}{c}\text { YEARS } \\
\text { WITH HF }\end{array}$ & $\begin{array}{l}\text { EMPLOYMENT } \\
\text { StATUS }\end{array}$ & $\begin{array}{c}\text { RePORTED } \\
\text { COMORBIDITIES }\end{array}$ \\
\hline 1 & Caucasian & 49 & Married & 12 & Disabled & None \\
\hline 2 & Caucasian & 64 & Widowed & 10 & Disabled & Anemia, depression \\
\hline 3 & Caucasian & 50 & Married & 2 & Disabled & $\begin{array}{l}\text { Coronary artery } \\
\text { disease }\end{array}$ \\
\hline 4 & Caucasian & 49 & Married & 4 & Disabled & $\begin{array}{l}\text { Coronary artery } \\
\text { disease }\end{array}$ \\
\hline
\end{tabular}

themes. Then with minor changes to syntax, $100 \%$ agreement among researchers was achieved.

\section{RESULTS}

The 4 participants in the study ranged in age from 49 to 64 years (Table). Two participants had nonischemic cardiomyopathy, and 2 developed HF postmyocardial infarction. All 4 participants completed high school, and 2 of the participants had completed some additional college. One participant lived alone, while the other 3 had the support of others living with them day to day.

As the data were analyzed, $5 \mathrm{mu}-$ tually exclusive themes emerged from the participants' description of living with HF: (1) developing a new conception of self, (2) conceding physical limitations, (3) enduring emotional heartache, (4) accepting support, and (5) rejuvenating through rest. The synthesized structural description of the lived experience emerged as a phenomenon that manifests with both physical and emotional distress, requiring these women to make multiple lifestyle adaptations, ultimately causing alterations to these women's view of self.

\section{Developing a New Conception of Self}

All of the participants reported that their experience with HF required them to develop a new self-concept. HF required 1 woman to "change [her] whole life" and was the catalyst for new "views," "opinions," and a new way of "looking at everyday things." Participants discussed how their life "was" before HF and how life "used to be" in recognition that HF created "a new way of feeling, of living." Being "sick" is part of who they are now. Women indicated they were no longer "a normal person," and coveted the old "quite healthy" self.

HF changed participants' views of self, secondary to changes in their daily activities. Participants described the need to "plan activities around how [they] feel," though they yearn "to be able to do things that [they] used to be able to do." Participants reported that they are now forced to view small daily tasks such as "doing dishes" or "making a meal" as positive accomplishments in a lifestyle confined by HF. One participant mourned that HF had infiltrated change into "every aspect of [her] life."

In addition to impacting daily activity, HF also altered the attainment of major life goals. For 1 participant, HF destroyed her hopes of becoming a mother. She indicated:

\section{Because my status was very serious when I was first diagnosed, my hus- band and I ... were advised to no longer. . . try to become pregnant. My heart was too weak to go through childbirth. I was sad, but I under- stood. It wasn't fair to bring a child into the world with ... such a very sick mommy .... Being a childless mother is a fallout of my CHF.}

All participants reported that HF changed their ability to be a produc- tive contributor to their home and profession. Being "trapped" by the physical limitations imposed by HF, 1 participant's hopes for eventual return to work "did not happen." Though their previous selves thrived on being "hard worker[s]" and being "on the go all the time," 1 participant came to realize that she was no longer a "go, go, go person." Another participant said that she can no longer work on a "regular" basis.

Roles lost as a consequence of HF were replaced by the realities of being ill. Now taking "an enormous amount of pills every day just to survive," participants "had to become comfortable with the way the [medications] made [them] feel." One participant indicated that she had grown accustomed to "bathroom runs through the night" because of diuretics, while another participant stated she kept a "pill box sitting next to [her] all the time." The constant companionship of an implantable cardioverter defibrillator was affectionately called "Charlie" by 1 participant. Although participants stated that they were previously unaware of "what CHF or cardiomyopathy was" before their diagnosis, 1 participant said she now realizes "what kind of condition [her] heart [is] really in and how it [is] never going to get any better."

\section{Conceding Physical Limitations}

Participants overwhelmingly reported limitations in their physical activity as a result of HF. Symptoms such as "fatigue" and "shortness of breath" 
resulted in their "inability to move very fast." One participant conceded that "It doesn't take much out [sic] walking around to become fatigued," while another stated that simply walking "from the bedroom to the living room" made her short of breath. One participant stated that when these symptoms occur "the body must win," forcing her to submit to her HF. Another participant admitted that she exchanges speed for endurance as she carries out her daily activities because if she " $\operatorname{tr}[$ ies] to put a little pep in the step, [she] get $[s]$ tired really easy."

When discussing the effects of physical limitations on their activities, all participants spoke specifically about the impact physical limitations had on their ability to complete housekeeping tasks. One participant said, "simple task[s]" like "carrying a basket full of laundry" have "become a chore." Another said, tasks such as "washing walls" or "dusting" that used to be finished in a day, "now [take] weeks" to complete. For most housekeeping tasks participants described just "do[ing] things slower," but still some tasks were too physically strenuous to perform.

\section{Enduring Emotional Heartache}

Participants consistently reported negative emotions in response to their HF that ranged from being "fearful" and "afraid" to being "depressed" and "frustrated." $\mathrm{HF}$ is a condition that 1 woman "hate[s]" but must bear because "there is nothing [she] can do about it." HF causes a "broken heart" leading to "thoughts and feelings that might [tear] you up inside." One participant acknowledged having "some very dark days over the years" and that much of the depression was caused by physical limitations. One participant said, "The most frustrating things for me are the limitations I have with [my grandson]. It sometimes makes me cry, because he wants me to do things that I can't [do].'

Three of 4 participants expressed anxiety related to what may happen in the future because of their HF. Real- izing her increased risk for mortality, 1 participant "chose not to fear what is coming down the pipe, but ... would be lying if [she] said it [did not] bother [her]." The threat of death and "suffer[ing] in the end" made 1 participant "stay scared every day." Ongoing symptoms of HF chased away "peace of mind" and exacerbate the fear of the future.

\section{Accepting Support}

Participants collectively reported accepting support as vital to their ability to cope with the manifestations of HF. "Friends" and a "close family" fulfill a "critical" need for "good and healthy relationships" and provide an outlet to "express ... thoughts and feelings" about HF. Support comes from others "understanding" their physical limitations. When 1 participant "needs help, [she] just ... ask[s]" and family "has to do" many household tasks she cannot complete. Participants reported that family members also provided support as they assumed a portion of the responsibilities of HF management. One participant said that her family members "watch [her] ... like a hawk" for signs of decompensation, while another indicated family members serve as "big cheerleader[s]," and "get after" her when she does not adhere to recommendations for her HF management. Bonds are strengthened as participants "realize how loved" they are by family and friends who support them through difficult periods.

\section{Rejuvenating Through Rest}

All participants indicated that obtaining adequate rest was important. The need to "sit down" or "lay $[s i c]$ down and rest" shadows every action: 1 participant stated she can "find a chair anywhere to sit, just to recharge for a minute or two." Rest is used for both long-term and short-term symptom control. To prepare for important family affairs, 1 women indicated she would "rest for days before that event" in order to "have the energy to be able to last" until the event is over. During acute exacerbation of symptoms another participant said that "rest must occur," and that she used it to alleviate her symptoms. When participants felt "fatigued" or "short winded" they would "sit down, prop [their] feet up, and ... do a crossword puzzle" until they felt "back to normal" and could resume their daily activities.

Participants also indicated they rejuvenated themselves through the rest acquired from sleep. Though sleeping with HF was often "challenged and interrupted," participants said that with more sleep they "might [have] a little more energy." After sleeping for "fourteen hours straight" 1 participant reported that she felt like she could "go out and beat up the world." Another participant described the rest she acquired through sleep as "a little slice of heaven."

\section{DISCUSSION}

This study provided a beginning to our understanding of the lived experience of middle-aged women with NYHA class III HF. The functional limitations were vividly described by the participants and served to increase our knowledge and awareness of how these limitations impact daily living. Similar to other studies, ${ }^{8,13,20-22}$ participants in this study reported fatigue as the most limiting symptom, followed by shortness of breath. Interestingly, women in this study tended to define their physical limitations by their ability to complete housework, providing further insight into the challenges faced by middle-aged women with NYHA class III HF in fulfilling their role as a homemaker.

Moreover, participants in this study reported the loss or alteration of other traditionally feminine roles. The loss of care-giving and nurturing abilities were difficult for the women to accept, a finding also reported by Stromberg and Martensson.' Additionally, this study identified that women with NYHA class III HF learned to accept support and care from others, care that they were often unable to reciprocate, due to physical 
limitations. In contrast to Martensson et al. ${ }^{12}$ who reported that women with HF perceived themselves to be a burden to others, participants in the current study reported that the care and concern received from others was needed and that they welcomed the support. These differences may be explained by differences in HF duration. Women in the current study lived with $\mathrm{HF}$ for a longer period of time (2-12 years), and therefore may be more accustomed to accepting support than women who were newly diagnosed ( 2 months to 2 years). ${ }^{12}$

Though unplanned, participants in the current study were all middle aged (age range $=49-64)$. This created an additional difference between this study and the 2 previous qualitative studies of women with $\mathrm{HF},{ }^{12,13}$ both of which interviewed elderly women (age range $=60-90$ ). Age likely played a major role in the desire of participants in this study to maintain professional activities, a finding not reported in previous qualitative studies with elderly subjects. Indeed, age may be more important to perceptions of career limitations than gender. Two qualitative studies of middle-aged males and females with $\mathrm{HF}^{23,24}$ noted that HF during middle age led to frustration regarding the loss of career roles.

As a consequence of major life role loss and limitations to daily activities, women in our study developed a new conception of self. This finding was similar to Nordgren et al. ${ }^{24}$ who also reported that middle-aged males and females developed a new self-image as a result of drastic limitations imposed by HF. Age may also play an important role in the similarity in these findings as individuals may have expectations of good health during middle age, expectations unfulfilled because of HF. Our findings reveal the powerful impact that HF has in changing middle-aged women's' perception of self.

Loss of role and limited functioning may be the impetus for emotional disturbances in women with HF, who struggled to find new value and meaning in their life. As 3 of the 4 women in this study reported being depressed, our study supports previous findings that emotional disturbances are common in adults with HF, especially among women. ${ }^{4,6,13,25}$ Depression among women with HF has been estimated to impact $35 \%$ to $64 \%$ of females. $^{7,26,27}$

\section{Implications}

Themes identified in this study suggest similarities in the lived experiences of these women with HF. As these women with $\mathrm{HF}$ realize the global impact of the disease, they could be assisted to accept and embrace a new self by making adjustments to their lifestyle within the limitations imposed by HF. By educating and counseling these women, nurses could assist them to find new ways to fulfill important personal, social, and professional roles. These women with HF could also be screened for depression and referred for treatment and professional counseling when indicated. Families could be taught how to best support their loved one's experience with HF.

When the burdens and losses of the disease feel overwhelming, nurses may be able to help these women evaluate and develop strategies to fulfill priorities. By helping these women find alternative ways to complete nonessential roles, increased capacity may be devoted to fulfilling roles they view as more important. Nurses may be able to play an important role in helping these women realize that adaptations to their lifestyle necessitated by HF may be a catalyst for strengthening key relationships and living a more purposeful and meaningful life.

\section{Study Limitations}

Three limitations of the current study were noted: the homogeneity of the participants, the disparity in length of time with HF, and the small sample size. Because this study used a convenience sample where participants were relatively homogeneous, results may not be transferable to diverse populations of women, such as those who are older or those who are of different ethnic or racial backgrounds. Additionally, the disparity in the length of time with HF among participants may be viewed as a limitation. However, no differences in perceptions were identified based on length of time with HF when comparing the participants who had HF for a shorter period ( 2 or 4 years) to those who had HF for a longer period of time (10 or 12 years). Similar to other phenomenological studies, which achieved saturation with a sample size of 4 participants, ${ }^{17,28}$ the narrative descriptions in this study were also detailed in nature and trends in redundancy in experiences were evident. However, replication of the study with a larger, multisite sample is recommended.

\section{Conclusion}

Living with NYHA class III HF is a complex phenomenon that required these women to develop a new conception of self as a consequence of physical limitations and emotional heartache induced by the disease and because of their need to accept support and obtain additional rest. This study provides a beginning to our understanding of the lived experience of women with NYHA class III HF. However, further exploration is needed to increase our knowledge of $\mathrm{HF}$ in women, as the conclusions of this study are based on the study sample and are not broad conclusions applicable to the general population of women with NYHA class III HF.

Acknowledgments: This study was supported by a research grant from Sigma Theta Tau International, Rho Chapter. The authors also thankfully acknowledge the women who willingly shared their personal experiences with HF. 


\section{REFERENCES}

1 American Heart Association. Heart disease and stroke statistics: 2006 update. Circulation. 2006; 113:e85-e151.

2 Luttik ML, Jaarsma T, Veeger N, et al. Marital status, quality of life, and clinical outcome in patients with heart failure. Heart Lung. 2006;35:3-8

3 Gott M, Barnes S, Parker C, et al. Predictors of the quality of life of older people with heart failure recruited from primary care. Age Ageing. 2006; 35:172-177.

4 Cline CM, Willenheimer RB, Erhardt LR, et al. Health-related quality of life in elderly patients with heart failure. Scand Cardiovasc J. 1999; 33:278-285.

5 Chin MH, Goldman L. Gender differences in 1year survival and quality of life among patients admitted with congestive heart failure. Med Care. 1998;36:1033-1046.

6 Riegel B, Moser DK, Carlson B, et al. Gender differences in quality of life are minimal in patients with heart failure. J Card Fail. 2003;9:42-48.

7 Gottlieb SS, Khatta M, Friedmann E, et al. The influence of age, gender, and race on the prevalence of depression in heart failure patients. J Am Coll Cardiol. 2004;43:1542-1549.

8 Ekman I, Ehrenberg A. Fatigue in chronic heart failure-does gender make a difference? Eur Cardiovasc Nurs. 2002;1:77-82.

9 Stromberg A, Martensson J. Gender differences in patients with heart failure. Eur J Cardiovasc Nurs. 2003;2:7-18.

10 Johansson P, Dahlstrom U, Brostrom A. Factors and interventions influencing health-related quality of life in patients with heart failure: a review of the literature. Eur J Cardiovasc Nurs. 2006;5:5-15.

11 Rector TS, Anand IS, Cohn JN. Relationships between clinical assessments and patients' perceptions of the effects of heart failure on their quality of life. J Card Fail. 2006;12:87-92.

12 Martensson J, Karlsson JE, Fridlund B. Female patients with congestive heart failure: how they conceive their life situation. J Adv Nurs. 1998;28: 1216-1224.

13 Rhodes DL, Bowles CL. Heart failure and its impact on older women's lives. J Adv Nurs. 2002;39: 441-449.

14 Hunt SA, Abraham WT, Chin MH, et al. ACC/ AHA 2005 guideline update for the diagnosis and management of chronic heart failure in the adult: a report of the American College of Cardiology/ American Heart Association Task Force on Practice Guidelines (writing committee to update the 2001 guidelines for the evaluation and management of heart failure). J Am Coll Cardiol. 2005; 46:e1-e82.

15 Husserl E. Cartesina Meditation: An Introduction into Phenomenology. The Hague, the Netherlands: Martinue Nijhoff; 1950.

16 Munhall PL. Phenomenology: a method. In: Munhall PL, ed. Nursing Research: A Qualitative Perspective. Sudbury, MA: Jones and Bartlett Publishers; 2001:123-184.

17 Boyd CO Phenomenology: the method. In: Munhall PL, ed. Nursing Research: A Qualitative Perspective. Sudbury, MA: Jones and Bartlett Publishers; 2001:93-122.

18 Giorgi A. An application of phenomenological method in psychology. In: Giorgi A, Fischer C, Murray E, eds. Duquesne Studies in Phenomenological Psychology, Vol. 2. Pittsburgh, PA: Duquesne University Press; 1975:82-103.

19 Giorgi A. Psychology as a Human Science: A Phenomenologically Based Approach. New York: Harper \& Row; 1970.
20 Bennett SJ, Baker SL, Huster GA. Quality of life in women with heart failure. Health Care Women Int. 1998;19:217-229.

21 Riedinger MS, Dracup KA, Brecht ML. Predictors of quality of life in women with heart failure. SOLVD investigators. Studies of left ventricular dysfunction. J Heart Lung Transplant. 2000; 19:598-608.

22 Wong M, Staszewsky L, Carretta E, et al. Signs and symptoms in chronic heart failure: relevance of clinical trial results to point of care-data from valHeFT. Eur J Heart Fail. 2006;8:502-508.

23 Evangelista LS, Kagawa-Singer M, Dracup K. Gender differences in health perceptions and meaning in persons living with heart failure. Heart Lung. 2001;30:167-176.

24 Nordgren L, Asp M, Fagerberg I. Living with moderate-severe chronic heart failure as a middleaged person. Qual Health Res. 2007;17:4-13.

25 Riedinger MS, Dracup KASOLVD Investigators. et al. Studies of left ventricular dysfunction. Quality of life in women with heart failure, normative groups, and patients with other chronic conditions. Am J Crit Care. 2002;11:211-219.

26 Freedland KE, Rich MW, Skala JA, et al. Prevalence of depression in hospitalized patients with congestive heart failure. Psychosom Med. 2003; 65:119-128.

27 Sherwood A, Blumenthal JA, Trivedi R, et al. Relationship of depression to death or hospitalization in patients with heart failure. Arch Intern Med. 2007;167:367-373.

28 Arslanian-Engoren CM. Lived experiences of CNSs who collaborate with physicians: a phenomenological study. Clin Nurse Spec. 1995;9:68-74. 